\title{
A Profile of College English Teachers' Attitude towards English as a Lingua Franca in China
}

\author{
Xu Beibei and Wang Zhuqing
}

\begin{abstract}
Some scholars in China argues that English as a Lingua Franca (ELF) pedagogical models are more suitable and efficient than English as a Native Language (ENL) ones. This paper is an empirical study of college English teachers' language attitude towards ELF and ELF-based pedagogical models in china. By combining questionnaire survey and individual interview together, this study shows that most college English teachers in China still prefer the ENL-based pedagogical model in their teaching and they are reluctant to accept China English as a new variety, although some of them show tolerance towards China English. It is hoped that this study can help to promote the ELF perspective in foreign language teaching and thus raise teachers' awareness of ELF.
\end{abstract}

Index Terms-ELF, pedagogical model, language attitude, China English.

\section{INTRODUCTION}

It is an undeniable fact that the spread of English makes it function as an international language with non-native speakers of the language outnumbering its native speakers. It is roughly estimated that only one out of every four users of English is a native speaker [1]. The global status of the English can be observed through its use as the language of business, technology, science, the Internet, entertainment, and even sports. For example, in the academic arena, more than half of the papers published each year are written in English and the percentage is also growing annually. Meanwhile, the globalization of English challenges native speakers' linguacultural norms and identities because English as a global language develops its idiosyncratic pronunciation, lexical or syntactic features when used in different countries as the official language or priority foreign language. The new varieties of English have been accepted and recognized in global communication especially among speakers who share neither a native language nor a national culture. It is a sociolinguistic reality that non-native English speakers are shaping English into Englishes. Under such circumstance, the term 'English as a lingua franca' (ELF) has emerged as a way of referring to communication in English

Manuscript received November 11, 2016; revised January 14, 2017. This work was supported in part by Qingdao Agricultural University under Grant XJP2013044 and Grant 1114Y50; Shandong Federation of Social Science Circles under Grant 15CWZJ33); Shandong Provincial Government Degree Committee under Grant SDYC15051.

$\mathrm{Xu}$ Beibei is with School of Foreign Languages, Qingdao Agricultural University, Qingdao, Shandong 266109 China. She is also with English Education Department, Korea University, Korea (e-mail: hsubeibei@gmail.com).

Wang Zhuqing is with School of Foreign Languages, Qingdao Agricultural University, Qingdao, Shandong 266109 China (e-mail: wzqlisa@163.com.). between speakers with different first language [2].

The concept of ELF also brings about changes in English Language Teaching (ELT), particularly in classroom teaching, which is the major channel for people to learn English as a foreign language. For many years, the Standard English (British or American English) were regarded as the only pedagogical norm for ELT. However, there has been a shift to new paradigm under the influence of ELF. The policy-makers and the researchers think that the teaching and learning of English should relate to the current spread and use of the language. Recently in China some scholars advocate a teaching model from an ELF perspective, yet the dominant norms in ELT practice are based exclusively on English as a Native Language (ENL) [3]. Wen, as an influential researcher of English education in china, proposes to bring the concept of ELF into classrooms of tertiary education in China and calls for more work to be done to meet pedagogical challenges in this context. Based on the framework of ELF, this study aims to examine college English teachers' attitude towards ELF based on the premise that teachers' language attitude decides their teaching practice and produces far-reaching impact on students' language acquisition. It is hoped that this research can shed some light on English education reform in China.

This study aims to investigate the following two research questions:

1) What's the college English teachers' language attitude towards China English?

2) What's their preferred model of ELT in classrooms, ELF-based or ENL-based? Why?

\section{Pedagogical Research Under ELF}

Pedagogical research is one of the foci of ELF studies. Compared with the traditional EFL perspective which takes British or American English as norms, ELF pedagogy suggests that the language learning goal become being able to use English successfully in lingua franca or multilingual contexts rather than to acquire standard forms and native-like proficiency [4]. Jenkins et al. (2011: 284) point out that while L1 interference and fossilization are assumed to be signs of incompetence when viewed from an EFL perspective, in ELF they are seen as crucial bilingual pragmatic resources [5].

Kirkpatrick (2006) identifies three pedagogical models of English in East Asia: a native speaker model, a nativised model, and a lingua franca model [6]. By discussing the advantages and disadvantages of these models, he concludes that the lingua franca one is most suitable in countries where English is used mainly by non-native speakers. However, he also argues that a native speaker model is still the choice in 
China due to Chinese officials and administrators' strong attachment to standards and correctness. Concerning the current context in China, Wen (2012) proposes an ELF pedagogical model which contains linguistic, cultural and pragmatic components. She points out that the English curriculum should provide the opportunity for people to learn not only the cultures of English speaking countries but also the cultures of their own region [3]. Her reasoning lies in the fact that most non-native speakers need to use English to discuss their own culture rather than the British or American culture. The use of English as the lingua franca highlights the need for an understanding of cultural contexts and communicative practices to successfully communicate across diverse cultures [7].

In order to respond to the new ELF pedagogical model, some scholars conduct research concerning ELF attitude in China [8], [9]. He \& Zhang (2010) discusses the relationship between native speaker norms and China English and conclude that native speaker models are the most desirable but they should be supplemented by the features of China English [8]. Wang (2013) investigates Chinese English users' attitudes towards the non-conformity to ENL and the result shows a slight positive tendency [9]. However, these researches are mainly carried out from the learners' perspective. English teachers as the stakeholders, whose attitudes and beliefs decide their teaching process, should also be included in the study. Thus, this paper raises the two research questions in the first part to investigate the College English teachers' attitude to ELF in China.

\section{METHOD}

For the purpose of exploring college English teacher's attitude towards China English and their preferred pedagogical models in classrooms, this paper focuses on findings retrieved from a questionnaire survey and individual interviews. This study combines quantitative and qualitative methods together.

\section{A. Participants}

Altogether 30 teachers from Qingdao Agricultural University (QAU) took part in the questionnaire survey and a total of 30 valid questionnaires were collected. One tenth of them $(N=3)$ were interviewed individually via email. The interviewees were selected according to their academic ranks, years of teaching and responses to some related questionnaire items.

\section{B. Questionnaires and Procedures}

First, the questionnaire was designed carefully by referring to the previous studies. The questionnaire was divided into three parts. The first part included some personal information such as age and academic ranks. In the second part, the participants were asked to finish an evaluation task containing 10 questions. They should rate the acceptability of some expression given in English on the criteria of Likert five-point scale (see Appendix 1). The purpose of this part is to elicit attitudes towards China English and whether they only referred to ENL norms in evaluation. The last part of the questionnaire is about teachers' attitude toward ELF in their teaching process, which also contains 10 questions. For convenience and better understanding, the questionnaire was conducted in Chinese.

The examples in the acceptability evaluation task were collected from different context. The examples 1, 3, 8, 9 were selected from China Daily (which is the most popular English newspaper published in China) as China English expressing special phenomenon or entities in the context of China. Examples 2, 4, 10 were collected from the websites, where they were widely used by young people in China as Internet jargons but regarded as negative examples of Chinese speakers' L1 transfer. Examples 5, 6, 7 were selected to show ELF users' nonconformity to ENL.

After the questionnaire has been designed, it was distributed to the participants via a major online survey website (ur.qq.com) in China. Then the data was collected and analyzed by using SPSS 24.0.

\section{RESUlts}

\section{A. Results of Acceptability Evaluation}

The mean value of the acceptability evaluation is shown in Table I with the Cronbach's Alpha $=0.787$. The mean for the evaluation task (mean=2.73, $\mathrm{SD}=1.0827$ ) shows that the participants' attitudes towards China English are almost in the middle, which indicates they are quite uncertain (3=uncertain) about whether the examples provided are acceptable or not. If we refer to the specific examples, we can find some interesting results, which are shown in Table II.

Examples $1($ mean=3.23), $3($ mean=2.80), 8 (mean=3.30), 9 (mean=3.53) are regarded as typical China English and used frequently in reporting cultures, politics and social realities related to the mainland China. However, the comparatively high mean value ( $5=$ completely unacceptable) shows college teachers in QAU tend to treat them as unacceptable English expressions. Contrary to this, examples $2($ mean=1.60), $4($ mean $=1.70), 10($ mean=2.10) which are usually regarded as Chinglish (Chinese English with L1 transfer) are more acceptable to the teachers in QAU. As for examples $5($ mean $=2.47), 6($ mean $=2.40)$, they are also more acceptable although both of them indicate grammatical deviation from the standard English. Example 7 (mean=4.20) which also shows the grammatical deviation (informations for information) is regarded as the most unacceptable item. To the teachers in QAU, it seems the grammatical non-conformity to standard English in sentences, for example, non-conformity to tenses, is more acceptable than non-conformity appears as a word without any context.

\begin{tabular}{lr} 
TABLE I: MEAN FOR THE ACCEPTABILITY EVALUATION TASK \\
\hline \hline$N$ (valid) & 30 \\
Minimum & 1 \\
maximum & 5 \\
Mean & 2.73 \\
Median & 3 \\
Std. Deviation & 1.0827 \\
\hline \hline
\end{tabular}

\section{B. Results of Language Attitude towards ELF}

This part reports the result of English teachers' language attitude towards ELF in QAU, which is illustrated in Table III. 
The items and answers are listed here just as the brief summary. The full text is provided in the Appendix.

TABLE II: MEAN FOR EACH ITEM IN THE EVALUATION TASK

\begin{tabular}{|c|c|c|c|c|c|c|c|c|c|c|c|}
\hline & & 1 & 2 & 3 & 4 & 5 & 6 & 7 & 8 & 9 & 10 \\
\hline$N$ & Valid & 30 & 30 & 30 & 30 & 30 & 30 & 30 & 30 & 30 & 30 \\
\hline Missing & & 0 & 0 & 0 & 0 & 0 & 0 & 0 & 0 & 0 & \\
\hline Mean & & 3.23 & 1.60 & 2.80 & 1.70 & 2.47 & 2.40 & 4.20 & 3.30 & 3.53 & 2.10 \\
\hline Std. Deviation & & 1.251 & .894 & 1.243 & .988 & 1.137 & .498 & .805 & 1.236 & 1.479 & 1.296 \\
\hline Variance & & 1.564 & .800 & 1.545 & .976 & 1.292 & .248 & .648 & 1.528 & 2.189 & 1.679 \\
\hline Minimum & & 1 & 1 & 1 & 1 & 1 & 2 & 3 & 1 & 1 & 1 \\
\hline Maximum & & 5 & 4 & 5 & 4 & 4 & 3 & 5 & 5 & 5 & 5 \\
\hline
\end{tabular}

\section{DisCUSSION}

\section{A. ENL Norms or ELF Norms}

Concerning the evaluation task, the result is a little bit surprising for me because the teachers' acceptability of Chinglish (Chinese English) is higher than other non-conformity to standard English, such as words expressing entities particularly in China (zongzi) and non-conformity to standard grammar (informations). Since in the questionnaire we did not ask the participant to state the reasons for their choice, we interviewed 3 participants to ask them why they believe that Chinglish expressions such as Good good study, day day up is more acceptable than zongzi and informations. Their answers are very similar and context-related. Although all of interviewees admit that Chinglish expressions are stupid and should be avoided in written language, they still think Chinglish are more acceptable because its use confines only to Chinese speakers who can fully understand such kind of word-for-word translation from Chinese to English. However, even though we cannot find the exact counterpart in English for zongzi, zongzi itself used as an English word can never be understood by foreigners without any detailed explanation. Meanwhile, they believe that standard grammar should be followed although some deviations do not cause misunderstanding.

The quantitative result and the interview show that college teachers in QAU have a tendency to become more tolerant towards China English although they still evaluate them from the perspective of ENL.

Two of the three interviews provide not only the reasons for their choices, but also the accurate usage of the 10 examples. They point out the 'grammatical errors' and replace them with the 'correct' expressions. It shows that some college teachers in QAU are more concerned with the ENL norms even though $67 \%$ of them admit the existence of China English. Over half of the participants do not believe and China English can become a separate variety of the English language. This kind of disbelief thus has an influence on their teaching processes.

Near half of the participants $(45 \%)$ feel shameful towards their Chinese accent when speaking English. Actually, Cogo (2011: 103) claims that the speakers' foreignness cannot be seen as a disadvantage [10]. From the perspective ELF, non-native speakers' different (and often multilingual) backgrounds provide them with invaluable resources and strategies, which they can draw upon to achieve their communicative purposes. This finding implies that the teachers in QAU are far from the understanding of ELF and they stick to the norms of ENL.
TABLE III: TEACHERS' LANGUAGE ATTITUDE TOWARDS ELF

\begin{tabular}{|c|c|c|}
\hline Item & Answers & Percentage \\
\hline \multirow{3}{*}{$\begin{array}{l}\text { English under } \\
\text { globalization }\end{array}$} & $\mathrm{BE} / \mathrm{AE}$ as norms & $62 \%$ \\
\hline & Englishes & $31 \%$ \\
\hline & No standard English & $7 \%$ \\
\hline \multirow[t]{3}{*}{ Chinese accent } & Shameful & $45 \%$ \\
\hline & Normal & $30 \%$ \\
\hline & Do not care. & $25 \%$ \\
\hline \multirow[t]{3}{*}{ Goals of Teaching } & Effective communication & $63 \%$ \\
\hline & Native-like & $25 \%$ \\
\hline & Pass examinations & $12 \%$ \\
\hline \multirow{3}{*}{$\begin{array}{l}\text { Variety used in } \\
\text { teaching }\end{array}$} & $\mathrm{BE}$ or $\mathrm{AE}$ & $60 \%$ \\
\hline & $\begin{array}{l}\text { English as native } \\
\text { (Australia) }\end{array}$ & $25 \%$ \\
\hline & $\begin{array}{l}\text { English as official or } \\
\text { second }\end{array}$ & $15 \%$ \\
\hline \multirow[t]{2}{*}{ errors } & Correct errors & $96 \%$ \\
\hline & Not correct & $4 \%$ \\
\hline \multirow{3}{*}{$\begin{array}{l}\text { quantity of Chinese } \\
\text { culture }\end{array}$} & appropriate & $35 \%$ \\
\hline & Not enough & $35 \%$ \\
\hline & Too much & $30 \%$ \\
\hline \multirow{3}{*}{$\begin{array}{l}\text { English introduction } \\
\text { of Chinese culture }\end{array}$} & agree & $50 \%$ \\
\hline & Not care & $27 \%$ \\
\hline & disagree & $23 \%$ \\
\hline \multirow{3}{*}{$\begin{array}{l}\text { Teaching Chinese } \\
\text { culture in English }\end{array}$} & necessary & $57 \%$ \\
\hline & uncertain & $23 \%$ \\
\hline & unnecessary & $20 \%$ \\
\hline \multirow[t]{3}{*}{ China English } & Exist but nonstandard & $67 \%$ \\
\hline & $\begin{array}{l}\text { Should conform to norms } \\
\text { of } \mathrm{BE} \text { or } \mathrm{AE}\end{array}$ & $23 \%$ \\
\hline & No China English & $10 \%$ \\
\hline \multirow{3}{*}{$\begin{array}{l}\text { China English as a } \\
\text { recognized variety }\end{array}$} & Never be recognized & $51 \%$ \\
\hline & Can be recognized & $20 \%$ \\
\hline & Not sure & $29 \%$ \\
\hline
\end{tabular}

\section{B. Pedagogical Models}

Effectiveness and efficiency are the core values of the pedagogical model under ELF. The survey shows that most college English teachers in QAU (63\%) believe that effective communication is their teaching goals rather than native-like fluency. Nevertheless, still $96 \%$ of them choose to correct students' non-native pronunciation errors, which shows their very high intolerance of non-conformity to ENL. The attitude towards teaching objectives and their teaching behaviors are contradictory to a certain degree. As Jenkins (2012: 489) points out, some deviations from ENL do not influence mutual understanding and have been regularized under ELF [11]. Wen (2012: 78) also claims that teachers should be more tolerable towards such deviations. It is obvious that the influence of ENL is still widespread among college teachers in China despite the fact that $31 \%$ of them admit the existence of Englishes and $40 \%$ believe that other varieties of English can also be used in teaching [3]. Globalization influences their attitude towards the English language and some teachers are more open to such changes under ELF.

Diversified culture learning is an important part in the ELF-based pedagogical models [7], [12]. Concerning the 
teaching of Chinese culture in English, 57\% of the participants believe the necessity because they find students' incompetence of introducing Chinese culture to foreigners. The interviewees also point out this problem, saying that the reason for students' incompetence is the syllabus where only the cultural knowledge of English speaking countries has been listed.

The interview shows that the best pedagogical model chosen by the three participants is still the ENL-based one although they say China English can be a kind of supplement. The reason for the adherence to ENL-based model is its long standing in English education in China. For a very long time, English to Chinese teacher is either British English or American English. Although they admit other varieties, BE or $\mathrm{AE}$ is their 'official' language in teaching. The interviewees also believe that the adherence to $\mathrm{BE}$ or $\mathrm{AE}$ is part of their identities as an English teacher. Moreover, the researches into ELF-based models are far from enough to formulate a system accessible to all the English teachers. The theoretical framework for ELF-based teaching is still under construction especially in China.

There are also some positive changes. From the survey we can see that some teachers are beginning to change their language attitudes and teaching ideas. The interviewees also show the willingness to be more tolerable to students' deviations.

\section{CONCLUSION}

The irrevocable globalization definitely exerts influence on language teaching and ELF model is being under research by many scholars abroad and at home. Wen (2012) proposes the ELF pedagogical framework and claims it will improve the efficiency and effectiveness of English education in China [3]. However, the findings of this study show that most college English teachers in China still prefer the ENL-based pedagogical model in their teaching and they are reluctant to accept China English as a new variety, although some of them show tolerance towards China English. Teachers are the organizer of the classroom activities and their language attitudes determines their pedagogical models. The results reflected in the survey demonstrate that college English teacher in china still need more time to accept and be familiar with the multicultural ELF teaching model.

The purpose of doing this survey is not about urging teaching English as a lingua franca. ELF is about awareness and choice, making students aware of different ways of speaking English and about offering choice to them, i.e. they can choose to speak like native speakers when and if they want to, but they may want to speak ELF in some contexts [10], [13]. It is hoped that this research can shed some light for the English education reform undergoing in China.

\section{APPENDIX}

\section{The Questionnaire}

Section 1: Personal Information

1) How old are you?

2) What's your academic rank?

Sections 2: acceptability evaluation task
Do you personally accept the following English expressions? Please state your evaluation of their acceptability. $5=$ completely unacceptable, $4=$ unacceptable, 3 = uncertain, 2 = acceptable, 1 = completely acceptable.

1) Zongzi (粽子)

2) Good good study, day day up. (好好学习， $\begin{array}{lllll}5 & 4 & 3 & 2 & 1\end{array}$ 天天向上)

3) migrant workers (农民工)

4) People mountain people sea.(人山人海)

5) She go to school every day.

6) Last year, I write a letter to my parents.

7) Informations

8) seek truth from facts (实事求是)

9) One country, two systems. (一国两制)

10) I'll give you some color to see see. (我要给 $\begin{array}{lllll}5 & 4 & 3 & 2 & 1\end{array}$ 你点颜色看看。)

Section 3: College English Teachers' Attitudes towards ELF

1) What do you think of English under the context of globalization? A. English should conform to the norms of British or American English.

B. There exist plural Englishes.

C. There is no standard English any longer.

2) How do you feel if your pronunciation of English carries Chinese accent?

A. Shameful

B. It's normal because it is difficult for a foreigner to learn native-like English.

C. Do not care about it.

3) What's main goal of English teaching?

A. To make learners communicate in English fluently.

B. To make learners approach the levels of the native speaker.

C. To make learners pass all kinds of examinations for further education.

4) Which variety of English should be used in foreign language teaching?

A. British English or American English

B. English as the native language, e.g. Australian English.

C. English as the official language or second language, e.g. English used in India, Philippines, Singapore etc.

5) There are some typical errors made by Chinese speakers, for example, the pronunciation of $[\theta]$ as [s]. Should such kind of errors be corrected? A. Yes B. No

6) How do you evaluate the quantity of Chinese culture reflected in the teaching materials you are currently using?

$\begin{array}{lll}\text { A. Appropriate } & \text { C. Not Enough } & \text { D. Too much }\end{array}$

7) What's your opinion on integrating more English introduction of Chinese culture into the textbooks?

A. Agree B. Don't care C. Disagree

8) What your opinion on teaching Chinese culture in English?

$\begin{array}{lll}\text { A. Necessary B. Uncertain C. Unnecessary } & \end{array}$

9) How do you think of China English?

A. China English does exist but it is nonstandard English.

B. China English should conform to native speakers' norms.

C. There is no China English

10) Can China English be recognized as a variety like American English? $\begin{array}{lll}\text { A. Yes } & \text { B. No C. Not sure }\end{array}$

\section{REFERENCES}

[1] D. Crystal, English as a Global Language, U.K.: Cambridge University Press, 2012.

[2] B. Seidlhofer, "English as a lingua franca," ELT Journal, vol. 59, no. 4, p. 339, Oct. 2005.

[3] Q. F. Wen, "Teaching English as an international language in mainland China," in English as an International Language in Asia: Implications for Language Education, A. Kirkpatrick and R. Sussex, Eds. Netherlands: Springer, 2012, pp. 79-93. 
[4] A. Kirkpatrick, "English as an Asian lingua franca and the multilingual model of ELT," Language Teaching, vol. 44, no. 2, pp. 212-224, Apr. 2011.

[5] J. Jenkins, A. Cogo, and M. Dewey, "Review of developments in research into English as a lingua franca," Language Teaching, vol. 44, no. 3, pp. 281-315, July 2011.

[6] A. Kirkpatrick, "Which model of English: Native-speaker, nativized or lingua franca," in English in the world: Global rules, global roles, R. Rubdy and M. Saraceni, Eds. U.K.: Bloomsbury Academic, 2006, pp. 71-83.

[7] W. Baker, "From cultural awareness to intercultural awareness: Culture in ELT," ELT journal, vol. 66, no. 1, pp. 62-70, Jan. 2011.

[8] D.Y. He and Q. Y. Zhang, "Native speaker norms and China English: From the perspective of learners and teachers in China," TESOL Quarterly, vol. 44, no. 4, pp. 769-789, Oct. 2010.

[9] Y. Wang, "Non-conformity to ENL norms: A perspective from Chinese English users," Journal of English as a Lingua Franca, vol. 2, no. 2, pp. 255-282, Apr. 2013.

[10] A. Cogo, "English as a Lingua Franca: concepts, use, and implications,” ELT Journal, vol. 66, no. 1, pp. 97-105, Jan. 2011
[11] J. Jenkins, "English as a lingua franca from the classroom to the classroom," ELT Journal, vol. 66, no. 4, pp. 486-494, Oct. 2012

[12] W. Baker, J. Jenkins, and R. Baird, "ELF researchers take issue with 'English as a lingua franca: An immanent critique'," Applied Linguistics, vol. 36, no. 1, pp. 121-123, Jan. 2015.

[13] J. Jenkins, "Current perspectives on teaching world Englishes and English as a lingua franca," Tesol Quarterly, vol. 40, no.1, pp. 157-181, Jan. 2006.

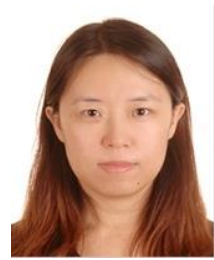

Xu Beibei was born in Shandong, China on March 1, 1980. She received her bachelor's degree in English education from Shandong Teachers' University, Jinan, China in 2002 and her master of arts in the field of English language and linguistics from Sun Yat-Sen University, Guangzhou, China in 2005.

She is now with the School of Foreign Languages, Qingdao Agricultural University in Qingdao, China. Ms. Xu is a member of Asia-Pacific Languages for Specific Purposes and Professional Communication Association. 